\title{
Making authors toe the line
}

The idea that those who wish to contribute to the scientific literature should first satisfy preconditions sends shivers down the spine: are there compromises to be worked out?

Databases have come to stay and, like many other institutional innovations, have roused great passions. So much is plain from the manner in which the supporters of particular databanks advocate their virtues - with zeal, sometimes with blind zeal. Only a few weeks ago, in a nice illustration of that genre, one correspondent found himself declaring that "it is a simple matter to require that the author of a sequence paper provides an accession number . . . as a prerequisite to publication" (Nature 342, 114; 1989). But is it?

So far as this journal is concerned, most passion centres on the decision that preconditions on the publication of research material are not simple. In particular, it has not hitherto been a precondition of the consideration of a manuscript for publication that nucleotide sequence data (if any) should first have been registered with one of the three branches (in Europe, the United States and Japan) of the international enterprise for compiling a coordinated nucleotide sequence databank. What follows is yet another explanation of what is plainly a contentious issue and of what some may even consider to be a remedy, this time evoked by the letter from Dr Lennart Philipson and his colleagues at Heidelberg (see page 849 ).

The first need, obscured in many of the arguments conducted in recent months, is that we should acknowledge the virtues of most databases, and of the nucleotide sequence databank in particular. It would be a great public service if there were a generally and uniformly available set of nucleotide sequences to which researchers could refer. Despite operational difficulties (many of them teething troubles) at the three centres, the service they provide is a good first approximation to a uniformly accessible sequence databank. There is good reason to expect that the arrangements now in place will be able to handle the much increased volume of data expected in the next few years. So far, it might be thought, so good. These are some of the reasons why this journal has, for several years, "urged" its authors to send their data to the sequence databanks. So why not go the whole hog, and make that a precondition?

This is not the arcane argument it may seem, but rather an issue of principle touching the relations between journals such as this and their contributors on the one hand and their readers on the other. It is not, of course, absurd, or an infringement of contributors' rights, that journals should require their contributors to satisfy certain preconditions - so many copies of a manuscript, typed in double-spacing, for example. Their justification is the mutual convenience of journals and their contributors that decisions should be reached quickly and that manuscripts chosen for publication should be as quickly processed. Tacitly, at least, such points are easily agreed.

Difficulties arise when contributors are asked to satisfy conditions that have nothing to do with the content of what they have to say, or the manner in which that is presented. Compliance with the wishes of the databanks is only one of the requirements that might be made of them. Why should not journals also demand, for example, that their contributors should have complied with the law? Would it not make for the tidier administration of regulations on the use of recombinant DNA techniques that the appropriate committees, if relevant, should have been notified and have given their approval? And the same, mutatis mutandis, for embryo research, the use of radioactive chemicals in the laboratory or the use of experimental animals in research? While they are at it, why should not journals also take on the administration of national legislation on secrecy?

Not all those who urge this journal to make mandatory the prior submission to databanks of nucleotide sequences would go so far as to applaud all possible innovations along these lines. An earlier correspondent (Nature 342, 114; 1989) correctly argued that the interaction between journals and their contributors, usually anxious to appear in print, is a point at which pressure can be effectively applied. But that is all the more reason why journals, rightly fearful of being turned into instruments of law-enforcement, should resist it. And the only simple recipe for the avoidance of the consequences of prior conditions on publication is that there should be none

Relations between journals and their readers are also important. The business of publication, which is an honourable and socially valuable business, is that of making information generally available. In principle, at least, all readers should be on an equal footing, with an equal chance to make what they can of what happens to be published. That is why this journal has, uniquely among journals with an interest in research, taken the trouble to print itself at three centres in world (so far). It remains a constant source of disappointment that the West Coast of the United States and Australia should be less quickly served than, say, New York or London.

Readers' appreciation of what they read depends, of course, on circumstances. People somehow in the swim are usually better placed to appreciate the full significance of what they find it interesting to read than those exiled to the sticks. Often it may be that a reader's understanding of a novel concept in a research article will fully flower only when he has talked it over with his or her colleagues, which is another kind of privilege. Most journals prudently acknowledge that these are circumstances they cannot change, much as they might wish to do so. But there are no circumstances in which a journal such as this, founded 120 years ago to bring the record of research to a wide audience, could fall in with the idea that its readers' appreciation of what they read will hang crucially on the accessibility of a databank in Heidelberg, Los Alamos or Mishima.

Accordingly, this journal has determined as follows: we shall continue (as at present) not to require of our contributors that they should have submitted their data (if in any way relevant) to the international databanks before submitting them for publication, but we shall threaten them that, if their articles appear in print and happen to be supported by nucleotide sequences, even if not intended to be published, we shall send those data off to Heidelberg or whichever other centre appears more congenial and also promises to make the data more generally available. We shall also make exactly the same data available to such of our readers who happen to telephone or to write. We shall do that without rancour, but shall aim to give the databanks a good run for their money. From time to time, we shall be willing to listen to people who have special secrets to hide.

This, then, is this journal's proposition: people with a nucleotide sequence to disclose should either disclose it or keep mum. They should not seek the best of both worlds, that in which they get credit for the sequence without saying what it is. Nor, for that matter, should they expect to be able to publish a sequence of nucleotides without being able to guess at what it means. Somewhere between, there must be a happy mean. Curiously, that boils down to an editorial function, not an issue of principle.

John Maddox 